\title{
APONTAMENTOS SOBRE A EXPANSÃO DA GRADUAÇÃO TECNOLÓGICA NO BRASIL
}

\section{NOTES ABOUT THE EXPANSION OF TECHNOLOGICAL GRADUATION IN BRAZIL}

José Deribaldo Gomes dos SANTOS ${ }^{1}$

Antonia Solange Pinheiro XEREZ ${ }^{2}$

RESUMO: Analisa a política de expansão da Educação superior no Brasil que, em tempos de reformas do Estado, opta pela precarização da universidade, enquanto valoriza a expansão da graduação tecnológica, objeto específico desta exposição. A opção teórico-metodológica recai sobre materialismo histórico-dialético, pois, do ponto de vista crítico, tal proposta é a que mais se aproxima da realidade, possibilitando ao investigador chegar o mais próximo possível do objeto estudado. Para efeito desta comunicação, serão recortados e submetidos a uma leitura imanente alguns documentos oficiais, bem como determinadas pesquisas que se empenham em debater o assunto.

PALAVRAS-CHAVE: Educação superior. Graduação tecnológica. Política pública. Educação profissional.

ABSTRACT: It analyzes the policy of expansion of Higher Education in Brazil. That once the State reforms it opts for the precariousness of the university while valuing the expansion of technological graduation. That is the specific object of this exhibition. The theoretical-methodological option rests on historical-dialectical materialism. From a critical point of view such a proposal is the one closest to reality, enabling the researcher to get as close as possible to the object studied. For the purpose of this communication, some official documents will be submitted to a reading, as well as certain researches that are engaged in discussing the subject.

KEYWORDS: Higher Education. Technological graduation. Public policy. Professional education.

${ }^{1}$ Universidade Estadual do Ceará - UECE (Quixadá, Ceará, Brasil); Titulação: Doutor; Av. Francisco Almeida Pinheiro, 2659, Planalto Universitário, Quixadá-CE. CEP: 63902-125; Telefones (85) 991815160; Email: deribaldo.santos@uece.br

${ }^{2}$ Universidade Estadual do Ceará - UECE (Fortaleza, Ceará, Brasil); Titulação: Doutora; Rua Professora Eloisa Ferreira Lima, 1865 - Serrinha, Fortaleza, Ceará, CEP 60742-105; Telefone (85) 32958802; Celular (85) 988274730; Email: antonia.xerez@uece.br 


\section{Introdução}

A trajetória da graduação tecnológica no Brasil se inicia um pouco antes do golpe empresarial-civil-militar de 1964. Muitas contradições, saltos, retrocessos e avanços ocorreram nessa história. Contudo, a documentação oficial mostra que esse subsistema de Ensino Superior (ES) ganha tessitura das políticas públicas para a sua implantação e desenvolvimento após a implantação do regime ditatorial. Não obstante a esse quadro, a chamada "cefetização" da Educação profissional, proposta pela lei $n^{\circ}$ 8.948/94, pode se constituir um marco dessa contraditória evolução. Conforme consta no $1^{\circ}$ artigo, $2^{\circ}$ parágrafo dessa lei, seus objetivos seriam:

Permitir melhor articulação da educação tecnológica, em seus vários níveis, entre suas diversas instituições, entre estas e as demais incluídas na Política Nacional de Educação, visando o aprimoramento do ensino, da extensão, da pesquisa tecnológica, além de sua integração aos diversos setores da sociedade e do setor produtivo.

Posteriores à lei retro citada, diversos outros dispositivos legais foram criados para garantir a estruturação definitiva no Brasil de uma educação de nível superior que formasse profissionais para ofícios laborais imediatamente conectados às exigências do mercado de trabalho. Segundo defendem os entusiastas desse tipo de graduação, agora seria necessário formar para a fábrica moderna "toyotizada", que passa a precisar de um empregado que se requalifique rápida e constantemente. Ainda conforme o discurso empresarial-governista, seria preciso atentar para as flutuações do mercado de trabalho. Portanto, no panorama que abre o século XXI, o tecnólogo se encaixaria na ideia central da flexibilidade "empreendedora", demandada pelo mercado capitalista contemporâneo. O objeto central do presente artigo é, portanto, analisar as contradições presentes no crescimento da graduação tecnológica brasileira.

Para que se possa atender a esse objetivo, não se pode desprezar, inicialmente, que como o complexo da política, da arte, entre outras esferas ideológicas, conforme entende Lukács (2013), a educação sistematizada decorre da relação capital-trabalho, o que lhe impede de ocupar sozinha a centralidade no papel de transformar a sociedade. A função do complexo educativo não tem como, numa sociedade capitalista, se desviar do papel de formar as consciências individuais para as necessidades demandadas do mundo da mercadoria. No entanto, se, por um lado, esse complexo não carrega a possibilidade ontológica de erradicar a sociedade de classes, por outro, resguardando a mesma 
perspectiva ontológica, é inegável que a educação desempenha importante função no processo de reprodução da sociedade, visto que opera um conjunto de mediações que possibilita ao indivíduo se apropriar, por meios de complexas mediações, à herança cultural acumulada pelo conjunto da sociedade.

Essa dialética leva a presente exposição entender que a natureza do complexo educacional apenas pode ser analisado intelectualmente quando mediado ontologicamente pelas contradições históricas a partir da relação causalidade-teleologia. Para problemas entrelaçados no plasma social é necessário penetrar além dos elementos aparentes. Esses pressupostos afiançam a presente comunicação a tomar por base o materialismo histórico-dialético, pois essa crítica é a que melhor ilumina a realidade, possibilitando chegar o mais próximo possível do que se pleiteia compreender. Entendese, portanto, que apenas uma metodologia que articule a história na sua processualidade material, considerando os avanços, saltos e retrocessos, pode descortinar o véu que dificulta a apreensão real da evolução da graduação tecnológica no Brasil.

Com base, destarte, nesse chão metodológico, a aproximação ao subsistema de ES especificamente profissionalizante, dar-se-á sobre o exame imanente de documentos oficiais, a exemplo, principalmente, das, Diretrizes Curriculares Nacionais (DCNs) para o nível tecnológico, Brasil (2002), Políticas públicas para a Educação profissional e tecnológica, Brasil (2004), Censo escolar da Educação superior 2010/2011, Brasil (2012, 2013), entre outros documentos estatais. O debate com algumas produções que se debruçam sobre o tema será utilizado para dar uma melhor sustentação às inferências da exposição. Recorta-se, para essa discussão, Takahashi e Amorim (2008), Neves (2012), Pacheco e Ristoff (2004), Giolo (2006), entre outras pesquisas.

Esses elementos permitem ao presente artigo indicar que o debate aqui desvelado contribui com a reflexão acerca do teor da atual expansão do ES no Brasil, cuja especificidade de uma graduação tecnológica tem privilegiada atenção das políticas públicas educativas. Mesmo que à guisa de introdução, a presente tematização considera que a graduação tecnológica guarda estreita relação com as necessidades do capital, cujo estágio contemporâneo amarga uma crise profunda. Pode-se apontar ainda que a elite nacional aplaude os incentivos governistas que, por seu turno, priorizam o alargamento do acesso à universidade por meio de cursos aligeirados, fragmentados, flexíveis, praticistas, voltando a abertura do ES para o "empreendedorismo" empresarial. 


\section{Terminologias, significados e conceitos: algumas considerações}

Para compreendermos a política expansionista da graduação tecnológica no Brasil, entendemos ser necessário iniciar pelo significado da expressão "qualificação profissional" no contexto da Educação profissionalizante, visto que esse subsistema do ES foi criado e desenvolvido - segundo argumentam seus defensores - para propiciar uma entrada mais rápida do jovem-trabalhador-estudante no mercado de trabalho. Esse argumento é repetido recorrentemente pelas políticas públicas educativas, que relacionam, por sua vez, a graduação tecnológica à necessidade de qualificar e requalificar o trabalhador para uma economia brasileira que estaria em câmbio constante. Segundo os defensores dessa política, tal economia não dispõe de mão de obra qualificada, o que justifica a expansão do ES por uma via não universitária.

Essa apresentação de fatores impõe a este artigo um necessário exame sobre alguns termos que cercam a denominada "Educação profissional". Conforme entende Lima Filho (1998, p. 3), essa terminologia é genérica e abrange vasta gama de processos educativos, "de formação e treinamentos em instituições e modalidades variadas". Essa dicção - assim grafada - é encontrada nos documentos oficiais como, por exemplo, o Capítulo III da Lei de Diretrizes e Bases da Educação (LDB), bem como no artigo $1^{\circ}$ do Decreto $n^{\circ}$ 2.208/97, que delibera sobre os objetivos da Educação profissional. O artigo $3^{\circ}$ desse decreto define que "[...] a educação profisssional compreende os seguintes níveis: básico, técnico e tecnológico". Para aquele autor, o emprego das expressões Ensino técnico e Educação tecnológica vai muito além de uma simples questão de semântica, pois reflete significações e concepções diferenciadas.

Apesar dessa denominação ser bastante usada nos documentos oficiais, foi por volta da segunda metade da primeira década do século XXI que a literatura referente ao tema, sobretudo aquela ligada ao Ministério da Educação (MEC), passou a utilizar a designação Educação Profissional e Tecnológica, expressando-as pela sigla (EPT). Essa denominação parece sinalizar para a necessidade de atender a um potencial caráter de integração entre a chamada profissionalização de nível médio e sua congênere no nível superior, pois seu aparecimento coincide exatamente com a disseminação do novo paradigma das políticas governistas de expansão do ES pela via não universitária.

É importante mencionar que, nos anos de 1990, ocorreu, no governo de Fernando Collor de Melo, uma transformação estrutural no âmbito do MEC. Em virtude da estreita relação entre o Ensino médio público e o Ensino profissional, esse Ministério 
decidiu operar uma mudança interna para atender a demanda potencializada pela expansão dos chamados cursos técnicos. Assim, em 1990, foi criada a Secretaria Nacional de Educação Tecnológica (SENETE), que dois anos depois foi alterada e passou a ser designada pelo nome Secretaria de Educação Média e Tecnológica (SEMTEC).

Quando a Secretaria de Educação Superior (SESu) transferiu a supervisão dos centros superiores tecnológicos para a SEMTEC, esta pasta passou a ser denominada Secretaria de Educação Profissional e Tecnológica (SETEC) que, por seu turno, passou a ser responsável somente por definir as políticas de qualificação e expansão da Educação profissional, ficando a cargo da Secretaria de Educação Básica a definição das políticas do Ensino médio. Segundo pesquisa de Takahashi e Amorim (2008, p. 220), a SETEC tinha a missão, de "[...] expandir a educação profissional de maneira a atender às necessidades de formação do trabalhador e ampliar o acesso às novas tecnologias." Esses autores lembram que, já em dezembro de 1999, o MEC editou a Portaria n ${ }^{\circ}$ 1.647/99, transferindo a supervisão dos CSTs da SESu para a SEMTEC. Foi, porém, com o decreto $\mathrm{n}^{\circ}$ 5.159/00 que a SEMTEC passou a ser denominada de SETEC.

Depois de entendermos como o MEC subdividiu em sua estrutura interna os setores que tratam da Educação profissional, em seus diversos níveis, e como foram redefinidas as funções de alguns de seus órgãos, propomos visitar as Diretrizes Curriculares Nacionais (DCNs) para o nível tecnológico, procurando entender o conceito que esse Ministério exprime para uma graduação tecnológica.

Conforme define o MEC, os cursos de formação de tecnólogo devem ser estruturados para atender aos diversos setores da economia, e devem abranger áreas especializadas, aliando teoria e prática. Esses cursos são“[...] programas de curta duração, de no mínimo dois anos, destinados a candidatos que tenham concluído o ensino médio ou equivalente.” (BRASIL, 2002, p. 16). Esse documento esclarece que os egressos de tal modalidade de ensino "poderão prosseguir seus estudos, após a aprovação em processo seletivo, nos programas de graduação (bacharelado) e de pósgraduação." As principais vantagens desse tipo de formação, como argumentam os documentos oficiais, são: capacitação técnica para "boa" colocação no mercado de trabalho; aperfeiçoamento da prática profissional; atualização das qualificações técnicas e acadêmicas; ampliação dos horizontes intelectuais; e duração específica (reduzida).

Admitindo que possa existir uma zona de indefinição entre o Ensino profissional de nível médio, o Ensino tecnológico e o Ensino superior, o documento em foco 
adianta-se sobre a questão, explicitando o seguinte: "Ao se estruturar uma proposta de formação de tecnólogo, é preciso evitar superposições e lacunas em relação aos cursos técnicos e em relação aos cursos superiores de formação de bacharéis”. (BRASIL, 2002, p. 24). Não obstante, a exposição governista enfatiza sua ideologia ao afirmar que o graduado em tecnologia é cada vez mais requisitado pelo chamado mundo do trabalho. Para tentar dirimir as dúvidas sobre as prováveis indefinições, o texto oficial escreve que a Educação profissional "integra às diferentes formas de educação, ao trabalho, à ciência e à tecnologia, conduz o cidadão ao 'permanente desenvolvimento de aptidões para a vida produtiva'." (BRASIL, 2002, p. 7, aspas do original). O MEC, sem receio de parecer redundante nesse aspecto, enfatizando a importância de uma formação superior em tecnologia ao esclarecer que o curso é essencialmente uma graduação “[...] com características diferenciadas, de acordo com o respectivo perfil profissional de conclusão [...]"(BRASIL, 2002, p. 26); e que "requer desenvolvimento de competências mais complexas que as do nível técnico, bem como, maior nível de conhecimento tecnológico." (BRASIL, 2002, p. 23, itálico nosso).

Procurando historiar a participação do tecnólogo no chamado mercado de trabalho, o discurso oficial aponta que esse profissional se fez notar inicialmente nas profissões relacionadas à Engenharia mecânica e à Engenharia de construção e, posteriormente, verificou-se sua atuação potencializada nas áreas de Eletroeletrônica, Informática, Biotecnologia e, por último, nos diversos campos de prestação de serviços. Quanto à sua performance, o tecnólogo cabe bem nos setores de comércio e serviços, pois constitui "um notável universo em expansão", como conclui o documento (BRASIL, 2002, p. 24).

A justificativa expressa pelas diretrizes sobre a necessidade de um curso de tecnologia que se situe entre o formado em curso profissionalizante de nível médio e o bacharel em Engenharia assume a posição de que as tecnologias de "ponta" exprimem articulação cada vez mais crescente com o conhecimento científico. Sendo assim, "o papel do tecnólogo, de quem se espera uma aptidão para a aplicação de tecnologias associadas à capacidade de contribuir para a pesquisa, se torna ainda mais estratégico". (BRASIL, 2002, p. 25). Essa justificativa fundamenta-se nas argumentações defendidas pelo engenheiro especialista em mecânica dos solos, Milton Vargas (apud BRASIL, 2002, p. 25-6), segundo o qual

As tecnologias, embora bem-sucedidas, são, em sua maioria, importadas. Esta talvez seja a razão da atual crise em nossa indústria e 
da necessidade que ela sente em adquirir competitividade internacional. Para isso, é possível que não nos faltem engenheiros, nem cientistas competentes e nem um operário habilidoso. $\mathrm{O}$ que evidentemente está faltando em nossos laboratórios de pesquisa são os tecnólogos. Isso comprova nossa tese de que tecnologia não é mercadoria que se compra, mas, sim, que se aprende.

Discursos similares aos de Vargas, pelo menos na concepção fantasiosa sobre a tecnologia, defendem a existência hoje, no Brasil, de uma preocupante falta de engenheiros. Por isso, o País teria que importar mão de obra. Sem poder aprofundar a querela, vale registrar uma flagrante contradição presente desses posicionamentos alarmistas: se falta engenheiro para garantir o desenvolvimento econômico do país, não seria mais lógico formar engenheiros em vez de tecnólogos? Mesmo que os defensores da expansão do ES pela via não universitária tenham a resposta para essa retórica, mas a escondam, não podemos deixar de destacar, mais uma vez, que a Educação não pode carregar sozinha os malefícios ou benefícios do desenvolvimento econômico.

É interessante notar a proximidade que há entre a posição de Vargas e a defesa feita, cerca de três décadas antes, pelo economista Bresser Pereira. Ambos fecham acordo sobre a importância do know-how - expressão de (PEREIRA, 1980, p. 203) para o desenvolvimento industrial brasileiro, razão pela qual, para ambos os autores, o País teria que importar recursos externos e, por conseguinte, tecnologia. O economista, em publicação feita nos anos de 1960, constata que o desenvolvimento industrial dos países de capitalismo desenvolvido foi realizado por meio da absorção de técnicas emergentes que, desde o seu aperfeiçoamento, foram adequadas às necessidades econômicas dos respectivos países. No Brasil, de modo contrário, entende Pereira (1980) que a tecnologia usada é importada e, portanto, desadaptada às necessidades locais, o que provoca profundas distorções econômicas, acarretando problemas na área de emprego.

O País precisa se desenvolver para importar menos tecnologia, como já reconhecido por Vargas com certa justeza, ainda que de forma carente dos elementos de contextualização e problematização do assunto. Ora, se o Brasil necessita produzir pesquisa científica que expresse melhores condições tecnológicas para a população, o mais coerente não será investir em pesquisa científica para tornar o país independente da compra de tecnologia dos países produtores de artefatos tecnológicos considerados de ponta? Não é isso, porém, o que ocorre, pois as práticas defendidas por Vargas (apud BRASIL, 2002), Pereira (1980) e as diretrizes do MEC mostram a disposição do Brasil para investir na chamada capacitação tecnológica. 
$\mathrm{Na}$ atual fase histórica, o ensino de graduação tecnológica faz eco às demandas plantadas pelo sistema do capital no campo da Educação. Em uma realidade de crise profunda, de agravamento da crise pelo recrudescimento do sistema de exploração do trabalho a níveis jamais vistos, o capital reordena suas estratégias de recomposição das taxas de lucro, o histórico dualismo educativo passa a operar com requintados ingredientes, para alcançar o perfil do modelo de competência e empregabilidade.

\begin{abstract}
Muito convincente, não fosse a conjuntura brasileira, com seus traços acentuados na segunda metade da década de 1990: a disseminação do novo paradigma de organização das corporações em nível mundial, a desnacionalização da economia brasileira, a desindustrialização, a transformação da estrutura do mercado de trabalho, a terceirização e a precarização do trabalho, a reforma do Estado e a restrição do público conjugada com a ampliação do privado, a flexibilização das relações trabalhistas o enfraquecimento das instituições políticas de mediação entre a sociedade civil e o Estado... (SILVA JUNIOR, 2005, p. 15).
\end{abstract}

Ao MEC e a alguns de seus intelectuais, possivelmente desprovidos dos elementos favorecedores de uma análise rigorosamente contextualizada sobre as condições reais, capazes de apontar o desenvolvimento da ciência e da tecnologia no plano das necessidades, vinculadas desde uma autonomia relativa ao complexo do trabalho, resta apenas insistir na crença, praticamente "religiosa", do desenvolvimento tecnológico como determinação central da sociabilidade atual. Essa falta de compreensão sobre a teia de infindas mediações que articula trabalho à tecnologia desemboca em um ufanismo tecnológico míope e apologético, como é possível constatar na seguinte passagem dos DCNs para a chamada graduação tecnológica:

Os grandes desafios enfrentados pelos países, hoje, estão intimamente relacionados com as contínuas e profundas transformações sociais ocasionadas pela velocidade com que têm sido gerados novos conhecimentos científicos e tecnológicos, sua rápida difusão e uso pelo setor produtivo e pela sociedade em geral. As organizações produtivas têm sofrido fortes impactos provocados pelo frequente emprego de novas tecnologias que, consequentemente, alteram hábitos, valores e tradições que pareciam imutáveis. (BRASIL, 2002, p. 26-7, itálico nosso).

Como resta claro, para o MEC, o desenvolvimento da ciência e da tecnologia tem autonomia sobre as demais esferas sociais, fazendo brotar do chão "neutro" da experiência social ou, mais diretamente da produção, "novos" e desafiantes problemas, independentes das vontades e conflitos inerentes à sociedade de classes.

Para acompanhar as "novas" transformações tecnológicas, atenderia adequadamente um "novo" modelo de Ensino superior: a graduação tecnológica com sua flexibilidade de currículo e menor duração. Por meio de um ensino organizado em 
"saberes" mais ágeis, formatados sobre uma proposta pedagógica "mais competente", permitindo uma formação mais ligeira, pretende-se garantir a propalada qualificação da mão de obra ante um cotidiano permeado pelas chamadas tecnologias mais avançadas. Essa proposta para o processo produtivo resolveria, em nosso País, segundo pensam seus defensores, o problema da escassez de trabalhadores qualificados que no presente emperra o desenvolvimento do Brasil; de quebra, solucionaria o problema do desemprego e ainda ampliaria o acesso ao Ensino superior.

A proposta de funcionamento apresentada pelo MEC para o ES tecnológico em relação aos professores, estudantes e sociedade, leva a se crer que as profundas reformas e políticas foram elaboradas para atender a demanda da classe empresarial ávida por ver seus lucros aumentarem. Nesses cursos reduzidos, os docentes devem atuar como "clientes exigentes" para formar um profissional com "habilidades e competências empreendedoras" a serem adquiridas e elaboradas com suportes nas "exigências do mundo produtivo". Esse profissional ainda deve ser capaz de enfrentar os desafios das "velozes transformações do mundo do trabalho, da sociedade e, mais, das condições cambiantes da vida profissional contemporânea." (BRASIL,2002, p. 30).

Depois de se entender que conceito o MEC atribui a um curso de graduação em tecnologia, e para se conceder maior abrangência ao debate, precisa-se aclarar a confusão conceitual praticada pelos reformistas que conferem à técnica e à tecnologia papéis contrapostos e contraditórios. Tal discussão deixará esta exposição em melhores condições de avançar sobre sua proposta de analisar os dados da Graduação tecnológica, perspectivando para onde apontam as estatísticas, visto que não é possível entender a que se propõe um curso dessa natureza sem antes analisar, mesmo que sinteticamente, o que significa conceitualmente tecnologia.

Desse modo, se por um lado a concepção idealista burguesa denota a técnica e a tecnologia como panaceia da humanidade, por outro, os alarmistas lhes atribuem a culpa por alguns dos maiores problemas existentes na contemporaneidade. Assim, com base em Álvaro Vieira Pinto (2008), intenta-se aclarar qual é o essencial sentido da técnica e da tecnologia para a sociedade. Para esse filósofo, as duas categorias são elaborações históricas da humanidade e, portanto, não possuem vida própria, dependendo das contradições de classe, agudizadas na sociedade capitalista que hoje vive uma crise jamais vista.

Nenhuma pesquisa que se pretenda séria pode negar a colaboração da tecnologia no conforto, na segurança, na produção de bens materiais e simbólicos, bem como em 
uma incomensurável quantidade de elementos entrelaçados ao nosso cotidiano, operados por dispositivos tecnológicos de toda ordem e espécie e que certamente melhoram a vida humana. Não se pode negar o fato da atual existência de um cabedal de técnicas disponíveis jamais vistas. Portanto, não é esse o intento desta exposição. Ao contrário, reafirma-se, peremptoriamente, a importância da técnica e da tecnologia para a humanidade. Como demonstrado por Vieira Pinto (2008), contudo, os seres humanos ficam maravilhados com o que seus sentidos podem apreender, da mesma forma como qualquer outro ser social em qualquer outra época da história. Depois que a pessoa humana criou suas primeiras ferramentas, tornou-se socialmente técnica, daí por diante, cada fase histórica posterior tem que ser necessariamente mais rica em aspectos tecnológicos do que a anterior. Como enfatizou Lukács (2010), é uma lei básica o fato de a história somente andar para frente.

Os serviços prestados pelos funcionários da ordem, independentemente da fase histórica que presenciam, funcionam analogamente. Essa sentença de Vieira Pinto (2008) comprova-se por meio da proximidade entre o pensamento de Vargas e a defesa de Bresser Pereira, vistos há pouco. Além desses dois autores, é interessante epigrafar a ideia de que alguns dos agentes individuais ou coletivos que deturpam a real categorização da técnica e da tecnologia o fazem porque são acometidos pela enfermidade da cegueira idealista; outros são motivados por má-formação subjetiva de caráter; ademais, há os que permanecem no equívoco pela combinação de ambos os fatores. Aqui, talvez figure a maioria (SANTOS, 2012).

Sobre o método para compreender adequadamente a problemática da tecnologia, Vieira Pinto (2008) alerta para o perigo das visões superficiais sobre a questão. É preciso olhá-la profundamente, pois a "aparência da razão excluída pela concepção alarmista decorre do fato de haver grandes massas humanas espoliadas mediante o emprego de procedimentos, instituições ou equipamentos técnicos", indica o filósofo. Vieira Pinto (2008, p. 158), entretanto, questiona o fato de que somente pela técnica em si, "porque o autor da espoliação identifica-se sempre com um grupo ou classe social que se vale dos instrumento s técnicos para a satisfação de seus fins."

Para um quadro, como denomina Vieira Pinto (2008, p. 291), de "estado de levitação", a ambivalência da tecnologia "demonstra-se muito apropriado para dar-lhe a aparência de divindade transcendente." Como a história já se encarregou de registrar, foi por via da espoliação, da pilhagem, do genocídio, entre outras diversas práticas de acumulação, que alguns povos se desenvolveram diferentemente de outros. Na era do 
capitalismo monopolista e de crise crônica do capital contemporâneo, essa evolução contribui para que o alarmante desnível de acúmulo de técnicas e tecnologias entre os países de centro e os de periferia permaneça e, se possível, aumente. A tecnologia "deve ser, por necessidade, patrimônio da espécie" humana (VIEIRA PINTO, 2008, p. 269). O problema jamais deve ser procurado na tecnologia em si, pois essa é uma condição da evolução humana, uma conditio sine qua non para a emancipação plena da humanidade. A alarmante precarização social que a conjuntura atual do capitalismo degusta não é motivada pelas máquinas constituídas pelo trabalho do ser social; a tecnologia não tem como carregar em si um aspecto moral de ser boa ou má. O emprego que se faz dela é essencialmente onde se há de procurar o cerne da questão, sobretudo, na aplicação das possibilidades que o maquinário põe a serviço do capital: garantir o acúmulo do lucro para uma privilegiada parcela da população mundial (SANTOS, 2012).

Com suporte nessas reflexões, entende-se que, em primeiro plano, ao se pleitear a suposta necessidade de o País adentrar a chamada "Era tecnológica", reivindicando prementes reformulações educacionais para que o complexo escolar possa acompanhar o desenvolvimento social a reboque da evolução da tecnologia, coloca-se a Educação secundarizada ao desenvolvimento econômico, em detrimento de um desenvolvimento integral da sociedade. Isso, em primeira instância, já cria sérios problemas, pois assume que o projeto de escola deve se subordinar aos ditames economicistas. Prova disso é o fato da chamada Educação profissional e tecnológica, incluindo a superior, ser transferida da esfera do Ministério da Educação para o Ministério da Ciência e Tecnologia com a interferência do Ministério do Trabalho em certos casos.

Como já argumentado, pretende-se do próximo item em diante, atualizar e analisar os dados sobre a expansão da precarização do ES.

\section{Alguns indicativos de crescimento precário do ensino superior brasileiro}

A relação Ensino médio EM/ES Ensino Superior mostra-se como um dos maiores gargalos da Educação brasileira. No Ensino fundamental, conforme dados de Clarissa Neves (2012), encontram-se 87,2\% de matrículas na esfera pública; já no Nível médio, esse número sobe para $88,1 \%$. O ES, por sua vez, inverte essa ampulheta, visto que a rede privada aparece com cerca de 76,6\% das matrículas, consoante informa boletim do IBGE (2010) sobre a Pesquisa Nacional por Amostra de Domicílios (PNAD). Alguns dados de pesquisadores independentes sobre o número de matrículas 
no ES são mais pessimistas: $19 \%$ no público, contra $81 \%$ no privado. Ainda com relação ao EM: sua crescente demanda é estimulada pelas políticas públicas e pelos discursos das agências transnacionais. Vale ressaltar que o EM público, sobretudo o noturno, já funciona há anos, e seu aprofundamento se deu, mais ou menos, no início dos anos de 1970 com a chamada compulsoriedade da profissionalização, formando comerciários, escriturários, auxiliares de escritórios, ajudantes de assessorias diversas, entre outras profissões precárias.

Consideramos que o ES brasileiro, em sua essência, é hoje um sistema complexo e diversificado de instituições públicas (federais, estaduais e municipais) e privadas (confessionais, particulares, comunitárias, filantrópicas), além dos arranjos das chamadas Parcerias-Público-Privadas (PPPs), compostas por institutos de pesquisa e ensino, pelas montagens de mestrados profissionais - já se fala em doutorado profissional -; Parceria-Privado-Privado (PPvPv), formados pelos escritórios de assessoria, pesquisa e captação de recursos, mas, nesses casos, geralmente públicos, entre outras formas. Somam-se a esse quadro institutos e fundações privados, atuando em nome do público exames vestibulares agendados e agenciados, universidades em shoppings, graduações pré-matinais, na madrugada, em fins de semana e diversos arranjos na chamada Educação a Distância $(\mathrm{EaD})$, entre outras.

De posse desse material quantitativo, exposto logo na sequencia, procurar-se-ão, no contexto das estatísticas do Instituto Nacional de Estudos e Pesquisas Educacionais Anísio Teixeira (Inep), informações que nos forneçam detalhes sobre a evolução da graduação tecnológica na realidade da expansão do ES. Desde esse ponto, se efetuará dialeticamente uma apreciação quantitativa e qualitativa, procurando observar qual a direção apontada pelas estatísticas sobre esse subsistema educativo no País. Tenciona-se relacionar o crescimento de tal graduação à evolução dos chamados bacharelados/licenciaturas clássicos, para assim fazer inferências sobre a direção apontada por tais indicativos numéricos.

Apenas para relembrar, se apreciou em Santos, Jimenez e Mendes Segundo (2013) o intervalo que vai de 1994 a 2004 da graduação tecnológica no Brasil (Tabela 1). Expressou-se também, naquela oportunidade a ideia de, que do ponto de vista estatístico, os indicativos são extraordinários. Naquele período, a evolução do subsistema tecnológico estava bem acima dos cursos considerados clássicos bacharelados e licenciaturas. Agora, ao se recordar alguns desses dados, cerca de uma década depois do fim daquele intervalo, pretende-se atualizar esse exame, procurando 
analisar se e como o crescimento se mantém. Ao longo do diálogo sobre o comportamento da curva de desenvolvimento do subsistema de ES, se buscará mediar as possíveis causas do seu comportamento.

Veja-se, para iniciar, alguns indicativos de crescimento do subsistema tecnológico, expostos na seguinte tabela:

Tabela 1: Relação de crescimento de vagas, cursos, concludentes e matrículas da graduação tecnológica

\begin{tabular}{|l|l|l|l|l|}
\hline Ano & Vagas & Cursos & Concludentes & Matrículas \\
\hline $\mathbf{1 9 9 4}$ & 23.861 & 261 & 7.896 & 57.816 \\
\hline $\mathbf{2 0 0 4}$ & 200.458 & 1.804 & 26.240 & 153.307 \\
\hline Aumento \% & 840,11 & 691,19 & 332,32 & 265,16 \\
\hline
\end{tabular}

Fonte: Giolo (2006).

Para melhor contextualizar a análise, mesmo correndo o risco de que ela se torne mais complexa, é necessário expor outros números. Em 2004, consoante informou o Inep, no Censo do ES de 2007, apenas 46,75\% do total de vagas ofertadas na graduação tecnológica foram preenchidos. O setor empresarial, nesse mesmo ano, amargava $58,23 \%$ de ociosidade na graduação tecnológica, um índice maior do que o número de desocupação geral. Esse número, no entanto, fica bem próximo da taxa de desocupação registrada pelas instituições privadas que ofereciam os bacharelados/licenciaturas clássicos: de 2003/2004 a taxa de desocupação estava perto de 48\%. Nesse mesmo ano, a alíquota inicial total de ocupação das graduações clássicas marcou 56,2\%.

Tabela 2: Taxa de desocupação do setor privado - Censo do ES de 2007

\begin{tabular}{|l|c|c|}
\hline Ano & Bacharelado Clássico & Graduação tecnológica \\
\hline $\mathbf{2 0 0 4}$ & $48 \%$ & $58,23 \%$ \\
\hline
\end{tabular}

Fonte: Brasil (2009).

Não por pura e simples coincidência, como enfatiza a Tabela 2, a taxa de ociosidade no ES privado, considerado clássico no Brasil, era de aproximadamente $50 \%$, quando foi homologada a Lei $\mathrm{n}^{\circ} 11.096$, que institui o ProUni, em 13 de janeiro 
de 2005. Pouco mais de dois anos após a promulgação dessa lei, no dia 24 de abril de 2007, o Decreto $\mathrm{n}^{\circ} 6.095$ foi editado com a finalidade de estabelecer diretrizes para a criação das instituições federais de educação tecnológica, para fins de constituição dos chamados (na época) institutos federais de Educação, Ciência e Tecnologia, denominados inicialmente de IFETs. Tal fator criou grande impulso estatal para a ampliação das vagas no ES pela via não universitária.

A expansão da Rede Federal de Educação Profissional e Tecnológica e sua transformação em institutos federais ocupa lugar privilegiado no quadro da expansão precária que se formou o Ensino superior brasileiro. Sua apresentação inicial, contudo, como não poderia ser diferente, foi sedutora e aperfeiçoadamente moderna em termos neoliberais, visto que conseguiu contar, de forma acrítica, mas não sem contradições, mesmo que em linhas gerais, com a participação dos gestores, técnicos-administrativos, professores e parcela do sindicato da categoria. Sua adesão foi quase total. Havia, dentro da instituição, um sentimento geral de que o antigo Centro Federal de Educação e Tecnologia (Cefet) que, por sua vez, quando deixou de ser Escola Técnica, não o fez sem contradições, teria que ser algo "grande, maior": teria que migrar, oficialmente, para o ES e para a pós-graduação.

Para que se possa demonstrar alguns aprofundamentos, observem-se mais alguns dados fornecidos pelo Inep (2010, 2011).

1 Enquanto as matrículas na graduação clássica cresceram, de 2006 a 2007 $(4,4 \%)$, no tecnológico o crescimento foi de $24,8 \%$, seis vezes aquela taxa; 2 o censo do Inep (2010) informa orgulhosamente que enquanto em 2001 os chamados cursos superiores tecnológicos somavam 69.797 estudantes matriculados; em 2010, esse número registrou um aumento de mais de dez vezes, pulou para 781.609 matrículas crescimento de 1019,8\%; 3 apesar do investimento maciço da iniciativa privada nesse "nicho de mercado", sobretudo em sua vertente à distância, as instituições federais de Educação superior (IFEs) registraram aumento no período de 2001 a 2010 de $481 \%$ na oferta de vagas. Do total de 63.481 matrículas em cursos tecnológicos das IFEs no ano de 2010, 47.439 (74.7\%) estão nos IFs e nos poucos Cefets restantes; 4 o censo do Inep (2011) confirma a tendência de crescimento no tecnológico (pela via estatal e privada). Entre 2010 e 2011, destaca-se o crescimento de 9,6\% dos cursos tecnológicos; 5 do total de 30.420 cursos de graduação, 17.031 (ou 56,0\%) são bacharelados, 7.911 (26,0\%) são licenciaturas e $5.478(18,0 \%)$ são tecnológicos; e 6 segundo o grau acadêmico, observase um incremento de 2,7\% nos bacharelados, enquanto os tecnológicos cresceram $9,6 \%$, 
o que corresponde a uma taxa de crescimento dos CSTs em relação aos bacharelados de 3,55 .

Embora ainda pareça complexo, agora já nos é possível demonstrar que o capitalismo periférico e atrasado brasileiro, na sua missão de defender o neoliberalismo de forma a se parecer moderno e atualizado, exibe dois pesos e duas medidas. No entorno de 2004, quando a ociosidade registrada no ES, seja ele tecnológico ou clássico, situava-se próxima aos $50 \%$, o que faz o Estado? Utiliza duas maneiras distintas para solucionar o problema.

Para melhor esclarecer esse ponto, destaca-se o que assinalam Santos, Jimenez e Mendes Segundo (2013, p. 304-4):

O Estado, opta, no caso dos bacharelados, historicamente mais prestigiados, apresentar como proposta de alargar as portas da "casa do saber", o ProUni, efetuando o embaralhamento entre as esferas pública e privada. Dito em uma palavra: escoa os recursos públicos para os bolsos dos afamados empresários da educação, como fez em 2004, por intermédio do financiamento, proporcionado por tal programa, de centenas de milhares de vagas para a esfera empresarial. Já com relação à desocupação amargada pelas empresas no ESNU, o governo age de forma diferenciada. Oferta pela via pública a graduação tecnológica, através principalmente da ifetização dos CEFETs e da proposta do Programa de Apoio a Planos de Reestruturação e Expansão das Universidades Federais (Reuni).

Antes de se avançar transpondo as estatísticas sobre os números da graduação tecnológica, precisa-se indagar qual o motivo que leva a atrasada elite que comanda o Estado brasileiro a optar por expandir a universidade pela via não universitária. Para melhor problematizar essa questão, vejamos os indicativos numéricos sobre esse subsistema na América Latina. Enquanto, nessa parte do mundo, consoante dados da UNESCO/IESALC (2006), o ESNU representava em meados dos anos 2000 aproximadamente $25 \%$ do total de estudantes matriculados no ES, no Brasil, do total de alunos matriculados (5.302.373), somente 458.834 eram registradas nas graduações tecnológicas, ou seja, apenas $8,65 \%$ do total de estudantes do ES, portanto, bem abaixo da dos indicadores da América Latina. Os dados do tecnológico brasileiro, em relação aos indicativos da América Latina indicam os motivos que levam a esfera estatal a optar pela expansão do ES pela via não acadêmica. Como se detectou em pesquisa anterior, os empresários brasileiros não tiveram a "competência" necessária para explorar esse "nicho de mercado" possibilitado pela graduação tecnológica. Assim, o Estado assume a empreitada, utilizando todo o aparato midiático disponível, para convencer os jovenstrabalhadores-estudantes de que esse subsistema é uma boa opção (SANTOS, 2012). 
O que está sendo encoberto pelas estatísticas, no entanto, é o histórico dualismo educacional da escola erguida sobre o capitalismo, que precisa se atualizar/modernizar para enfrentar a crise do capital contemporâneo. Com relação a outros países da América Latina, o Brasil está bastante aquém das expectativas das agências transnacionais no que se refere à oferta de ES aos filhos dos trabalhadores pela via não universitária. Tal fato, portanto, motiva o Estado a promover a expansão do ES pela via não universitária de modo que possa ao menos se aproximar do montante verificado na América Latina, bem como atender à atualização e à modernização neoliberal do ES brasileiro, seguindo as orientações imperialistas por intermédio das agências transnacionais em articulação com o empresariado local.

Para que possamos demonstrar a orientação de tais agências sobre o ES brasileiro, utilizamos a pesquisa de (PAIVA, 2016, p. 112), cuja análise sobre documentos do Banco Mundial ponta que a educação terciária “é concebida como a ferramenta por excelência capaz de criar, divulgar e aplicar o conhecimento de uma maneira eficaz e de capacitar força de trabalho técnica e profissional.

Uma importante publicação do Banco Mundial, que traça as diretrizes para a educação superior, foi lançada em 2003 e tem como título: "Construir sociedades do conhecimento: novos desafios para a educação terciária." Tal documento reafirma o paradigma de que nas sociedades afetadas pela rápida globalização, o conhecimento é a mola propulsora das economias do século XXI e a chave para a redução da extrema pobreza. (PAIVA, 2016, 111-2)

Para o BM um ensino terciário aos moldes da graduação tecnológica incrementaria a capacidade do formando "para responder com flexibilidade as novas exigências das sociedades do conhecimento (BANCO MUNDIAL, apud PAIVA, 2016, p. 112).

Já o documento "La Enseñanza Superior: las lecciones derivadas de la experiencia” publicado por este Banco em 1995, já antecipava que o termo ensino terciário deve ser equiparado ao ES. Essa expressão pode ainda ser equivalente ao termo pós-secundário, em que se engloba as modalidades posteriores ao ensino médio. Entretanto, como adverte Paiva (2016, p. 111), "partimos do pressuposto que esta denominação não é meramente sinônima, mas possui a intencionalidade de valorizar as instituições não universitárias em detrimento das universidades que se caracterizam pela indissociabilidade entre ensino, pesquisa e extensão. Não é oneroso repetir que o ESNU, por sua natureza praticista e imediatista obstaculariza a integração entre esses três pilares universitário. 
Não é possível deixar fora desse foco de análise, como já registrado, as comparações amplamente divulgadas por publicações de vários organismos que mostram o Brasil, quando comparado com o panorama internacional, mesmo entre os países latino-americanos, em uma posição bastante desfavorável, quando a avaliação quer detectar a quantidade de jovens na faixa etária de 18 a 24 anos frequentando o ES. Pacheco e Ristoff (2004) - dois intelectuais ligados ao MEC - escreveram, em publicação de 2004, que, mesmo se triplicássemos os números de matrículas nas universidades brasileiras, teríamos ainda índices menores do que os da Argentina e os do Chile. Para ajudar a resolver esse problema, os autores indicam a expansão, sob responsabilidade do Estado, do ES brasileiro pelo caminho da graduação tecnológica, entre outras formas não universitárias.

Jaime Giolo foi coordenador-geral de estatísticas da Educação superior do Inep, e é um outro intelectual que apoiou esse tipo de expansão. Depois de verificar cuidadosamente os dados fornecidos por esse Instituto, exibiu algumas conclusões e declarou que: "[...] há ainda uma grande demanda constituída e outra a constituir, mas elas só poderão ser atingidas por meio das iniciativas públicas. Pois, a iniciativa privada não tem condições de atender plenamente a satisfação da população que busca a formação tecnológica.” (GIOLO, 2006, p. 133). Outros documentos do MEC, nessa mesma época, recomendavam a expansão da universidade pública pela opção não acadêmica. O caso mais figurativo foi o do documento "Políticas públicas para a educação profissional e tecnológica", que propõe uma série de benefícios para os estudantes que escolherem essa formação superior (BRASIL, 2004).

Somam-se a isso vários outros discursos que soaram na mesma direção, a exemplo, cada um ao seu modo específico, de Takahashi e Amorim (2008), Clarissa Neves (2012), Claudio de Moura Castro (2005), entre muitos outros defensores da expansão do ES pelo caminho não universitário. Portanto, várias manipulações de dados e defesas públicas de intelectuais ligados ao MEC/Inep, bem como de intelectuais “independentes”, apoiaram o discurso de expansão estatal do ES pela via precária; isto é, ajudaram a sustentar a ideia de que o mercado não tem condições de administrar o ES não universitário sozinho, sem a ajuda preciosa do Estado.

Apenas para ilustrar os discursos em defesa da ampliação de vagas no ES brasileiro pela via dos chamados CSTs, expõem-se aqui as palavras conclusivas da pesquisa publicada por (NEVES, 2012, p. 26): 
Uma alternativa que deve ser debatida é o investimento no aluno, através de bolsas ou outras formas viáveis de financiamento ao aluno. Outro aspecto importante para atender a nova demanda é intensificar a diversificação da oferta do ensino superior, não apenas a tradicional oferta de bacharelado e licenciatura, mas também investir em cursos tecnológicos, vocacionais, de curta duração, atendendo demandas imediatas e necessárias do mercado de trabalho.

São raras, entretanto, as análises rigorosas que mostram o incentivo estatal ganho pelo setor privado com esse tipo de política. Além disso, há uma imensa demanda reprimida, sem que o Estado neoliberal possa atender, como ficou demonstrado na quantidade de egressos do EM. Com efeito, ao divulgar a importância de um subsistema de ES como alternativa aos filhos da classe trabalhadora, o Estado atrai os jovens das camadas populares para a precariedade na formação superior. Serve como exemplo dessa atração a enorme propaganda retórica de aligeiramento, fragmentação e profissionalização precoce do EM, acenando, em contrapartida, para o fato de que agora já existem cursos superiores para essa "clientela": egressos da união da modalidade profissional com o nível médio, pomposamente denominada de Escola Integral, que hoje se espalha acriticamente por todo o Brasil.

Para esta pesquisa, a atrasada elite brasileira convence o Estado a preferir o que mais atende ao empresariado em detrimento de uma verdadeira e necessária expansão da universidade pública, gratuita, laica e de qualidade. A elite mandatária das políticas governistas não se importa se a educação brasileira é boa ou ruim. Para essa anacrônica elite, o processo educativo tem que gerar dinheiro como qualquer outro negócio. Os atrasados empresários brasileiros não nutrem interesse algum pelo desenvolvimento científico do País, como muito bem registrou o senhor João Uchôa Cavalcanti Netto (2001, p. 1), em polêmica entrevista vinculada pelo jornal Folha Dirigida: "A pesquisa é uma inutilidade pomposa, uma perda de tempo." Para que essa declaração de ingênua sinceridade não seja mal entendida, precisamos esclarecer que esse senhor foi o fundador da Universidade Estácio de Sá, instituição de ensino superior que mais cresceu no Brasil nas últimas quatro décadas. A declaração de João Uchôa é apenas um exemplo, entre tantos outros, a indicar que, para os atrasados empreendedores brasileiros, lucrar com esterco, com ração, com leite, ou com números de matrículas do ES, seja ele clássico ou não universitário, dá no mesmo. Somente o que lhes importa é o lucro. Ciência ou tecnologia podem até ter alguma importância, mas somente para impulsionar as vendas de um produto qualquer (SANTOS, 2012). 
A expansão do ES no Brasil está se processando pela via precária, isto é, pela cópia, como diz Frigotto (2006), ou, como já advertia Florestan Fernandes nos anos de 1960: pelo atraso. Com efeito, para sintetizar a precariedade de tal expansão, empregouse as ácidas palavras de Francisco de Oliveira (2003), quando se referiu à elite brasileira: o atraso da vanguarda e a vanguarda do atraso.

\section{Considerações finais}

A expansão do ES brasileiro ocorre pela opção empresarial, visto que a pedagogia das empresas (competências), o léxico dos empresários (empreendedorismo, testes de alto impacto, economia baseada no conhecimento, avaliação por via dos resultados) assaltam o mundo escolar como jamais visto.

Respaldada no axioma do falso socialmente necessário, a elite local e seus ventríloquos celebram uma suposta era tecnológica (Sociedade do conhecimento, Era informática), cuja discussão teórica não debate o que é ontologicamente técnica e tecnologia. Tal resulta em obscurecimento da realidade, contribuindo, portanto, com os interesseiros imperialistas que, por uma condição histórica, são os produtores de tecnologias. Tais interesses procuram intertravar a educação nacional à condição de subalternidade, pois, ao mesmo tempo em que precariza completamente a universidade, investe fortemente em uma via não universitária com recursos, infraestrutura e principalmente retórica pública da importância de uma expansão pela via do atraso.

Por fim, para piorar o quadro já descrito, até autores defensores das atuais políticas públicas governistas de expandir a universidade pela via precária, a exemplo de Clarissa Neves (2012), dizem que a expansão recente revela que o acesso ao ES continua concentrado nos jovens brancos, oriundos das camadas de faixas de renda alta e média.

Antes de finalizar, contudo, precisa-se exprimir a noção de que a escolha da expansão pela via não científica desvaloriza a universidade como campo de formação abrangente e crítica, como produtora da ciência básica, que precisa ser desenvolvida sem interesses imediatamente aplicáveis ao capital. Esta realidade avaliza no lugar da elaboração de um conhecimento verdadeiramente crítico, do espaço público e do dissenso, um recinto adequado ao agenciamento de uma qualificação apequenada, de solidez praticamente nula, alinhada a uma pretensa polivalência, além de atada às 
demandas de curto prazo, razões pelas quais jamais poderá colaborar com opções de superação da ordem mercadológica. Para se ser rigoroso, em última instância, nem polivalentes os trabalhadores sairão, pois, perante essa lógica, o alijamento da mão de obra permitirá tão somente o intertravamento da dependência brasileira ao imperialismo globalizado (SANTOS, 2012).

Este artigo, no entanto, não pode cair no vão comum de acreditar, como defenderam os intelectuais ligados ao MEC, que o Estado abarcará o ES não universitário porque o empresariado do setor educativo foi "incompetente" para administrar o "nicho de mercado" educacional aberto pelas graduações tecnológicas no Brasil. É preciso registrar, para que não reste dúvida alguma, o fato de, que o caráter abreviado de uma pesquisa avaliativa sobre uma política pública educacional no panorama neoliberal, globalizado e pós-moderno brasileiro precisará de constantes atualizações.

Perspectiva-se, outrossim, a ideia de que políticas públicas, a exemplo do Programa Nacional de Acesso ao Ensino Técnico e Emprego (Pronatec, lei $\mathrm{n}^{\circ}$ 12.513, de 26/10/2011), passarão a fazer parte das elaborações daquele Ministério e dos que o cercam. Mais: uma provável proposta estatal desembocará no financiamento público dos CSTs. Isto é, como já se adiantou, “o Estado brasileiro deverá oferecer incentivos financeiros aos empresários do ES para que eles ofertem ou, para os que já oferecem, aumentem o número de vagas disponíveis para a graduação tecnológica e seus assemelhados." (SANTOS, 2012, p. 168).

Assume-se o risco da tarefa do fazer crítico ao se perseguir a verdade na aparência confusa dos fenômenos. Assentados, contudo, em posição contrária à neutralidade científica, que ao mesmo tempo faz justiça ao construto teóricometodológico que se escolheu seguir, tem-se segurança em firmar as inferências. Portanto, esta pesquisa desmascara, no caso da problemática aqui tratada, as intenções do Estado brasileiro de ofertar, como expediente para aumentar os pífios indicadores da quantidade de jovens de 18 a 24 anos de idade que frequentam o ES, a opção pela graduação tecnológica. Fica inequivocamente aclarado também o fato de que tal opção segue prerrogativas empresariais da tosca elite local.

\section{Referências}


BANCO MUNDIAL. La Enseñanza Superior: las lecciones derivadas de la experiencia. Washington, D.C: Banco Internacional de Reconstrucción y Fomento / Banco Mundial, 1995. Disponível em: <http://www-wds.worldbank.org/external /default/WDSContentServer/WDSP/IB/2005/06/14/000090341_20050614161209/Rend ered/PDF/133500PAPER0Sp1rior0Box2150A1995001.pdf>. (Série: El desarrollo em la práctica). Acesso em: 3 mai. 2016.

BRASIL. Ministério da Educação. Conselho Nacional de Educação. Diretrizes curriculares: nível tecnológico. Brasília, DF, 2002.

BRASIL. Ministério da Educação. Políticas públicas para a Educação profissional e tecnológica. Brasília, DF, 2004.

BRASIL. Ministério da Educação. Censo escolar da Educação superior 2007. Brasília, DF: Inep/Deaes, 2009.

BRASIL. Ministério da Educação. Censo escolar da Educação superior 2010: resumo técnico. Brasília, DF: Inep/Deaes, 2012.

BRASIL. Ministério da Educação. Censo escolar da Educação superior 2011: resumo técnico. Brasília, DF: Inep/Deaes, 2013.

CASTRO, Cláudio de Moura. Os communitycolleges: uma solução viável para o Brasil? Brasília: Inep, 2000.

FARIAS,Aracélia C.; SANTOS, Deribaldo; FREITAS, Maria Cleidiane C. Ensino médio integrado no Estado do SANTOS, Deribaldo et al (Orgs). Educação pública, formação profissional e crise do capitalismo contemporâneo. Fortaleza: EdUECE, 2013.

FERNANDES, Florestan. A revolução burguesa no Brasil: ensaio de interpretação sociológica. 5.ed. São Paulo: Globo, 2006.

FOLHA DIRIGIDA (2001). Universidade e ignorância. Observatório da Imprensa. Disponível em: <http://www.observatoriodaimprensa.com.br/artigos/asp21112001994.htm>. Acesso em: 21 abr. 2011.

FRIGOTTO, Gaudêncio. Universidade pública, trabalho e projeto de desenvolvimento no Brasil sob o pêndulo da regressão social. In: MOLL, Jaqueline; PALMIRA, Sevegnani. Universidade e mundo do trabalho. Brasília: Inep, 2006. (Coleção Educação Superior em Debate, 3).

GIOLO, Jaime. A educação tecnológica superior no Brasil: os números de sua expansão. In: MOLL, Jaqueline; PALMIRA, Sevegnani. Universidade e mundo do trabalho. Brasília: Inep, 2006. (Coleção Educação Superior em Debate, 3).

INSTITUTO BRASILEIRO DE GEOGRAFIA E ESTATÍSTICA (IBGE). Pesquisa Nacional por Amostra de Domicílios (PNAD): síntese dos indicadores de 2009. Brasília, DF, 2010. 
LIMA FILHO, D. L. Os organismos internacionais e a Educação profissional: investigação sobre os determinantes da Reforma da Educação Profissional no Brasil. 1998. Tese (Doutorado) - Universidade Federal de Santa Catarina, Florianópolis, 1998.

LUKÁCS, Georg. Prolegômenos para uma ontologia do ser social: questões de princípios para uma ontologia hoje tornada possível. São Paulo: Boitempo, 2010.

LUKÁCS, Georg. Para uma ontologia do ser social II. São Paulo: Boitempo, 2013.

NEVES, Clarissa Eckert Baeta. Ensino superior no Brasil: expansão, diversificação e inclusão. Preparado para apresentação no Congresso da LASA (Associação de Estudos Latino Americanos) - São Francisco, Califórnia, 2012. Disponível em: <www.ufrgs.br/geu/Artigos\%202012/Clarissa\%20Baeta\%20Neves.pdf>. Acesso em: 22 abr. 2013.

OLIVEIRA, Francisco de. Crítica à razão dualista: o ornitorrinco. São Paulo: Boitempo, 2003.

ORGANIZAÇÃO DAS NAÇÕES UNIDAS PARA A EDUCAÇÃO, CIÊNCIA E CULTURA (Unesco). Informe sobre laeducación superior en América Latina y el Caribe 2000-2005: lametamorfosis de laeducación superior. Caracas: IESALC, 2006.

PACHECO, Eliezer; RISTOFF, Dilvo I. Educação superior: democratizando o acesso. Brasília: MEC/Inep, 2004.

PAIVA, Aline Nunes. O viés mercadológico do programa de educação para todos: uma análise onto-crítica das políticas educacionais brasileiras. Dissertação - (Mestrado) Universidade Estadual do Ceará, Faculdade de Educação Ciências e Letras do Certão Central e Faculdade de Filosofia Dom Aureliano Matos UECE/FECLESC/FAFIDAM. Limoeiro do Norte/CE, 2016.

PEREIRA, Luiz Carlos Bresser. Desenvolvimento e crise no Brasil. São Paulo: Brasiliense, 1980.

SANTOS, Deribaldo; JIMENEZ, Susana; MENDES SEGUNDO, Maria das Dores. O ideário educacional competente no contexto da crise estrutural do capital. Cadernos de Pesquisa em Educação PPGE-UFES, v. 17, p. 9-33, 2011.

SANTOS, Deribaldo; JIMENEZ, Susana; MENDES SEGUNDO, Maria das Dores. Graduação tecnológica no Brasil: crítica à expansão do ensino superior não universitário. Curitiba: CRV, 2012.

SANTOS, Deribaldo; JIMENEZ, Susana; MENDES SEGUNDO, Maria das Dores. Concepções epistemológicas e onto-históricas da técnica e da tecnologia: um debate no legado de Álvaro Vieira Pinto. In: SANTOS, Deribaldoet al. (Orgs.). Educação pública, formação profissional e crise do capitalismo contemporâneo. Fortaleza: EdUECE, 2013.

SILVA JUNIOR, João dos Reis. Pragmatismo e populismo na Educação superior: nos governos de FHC e Lula. São Paulo: Xamã, 2005. 
TAKAHASHI, Adriana Roseli Wünsch; AMORIM, Wilson Aparecido Costa de. Reformulação e expansão dos cursos superiores de tecnologia no Brasil: as dificuldades da retomada da educação profissional. Ensaio: Avaliação de Políticas Públicas em Educação, Rio de Janeiro, v. 16, n. 59, p. 207-228, abr./jun. 2008.

VIEIRA PINTO, Álvaro. O conceito de tecnologia. Rio de Janeiro: Contrapontos, 2008.

\section{Como referenciar este artigo}

SANTOS; José Deribaldo Gomes dos; XEREZ; Antonia Solange Pinheiro. Apontamentos sobre a expansão da graduação tecnológica no Brasil. Revista on line de Política e Gestão Educacional, Araraquara, v.20, n.03, p. 600-622, 2016. Disponível em: <http://dx.doi.org/10.22633/rpge.v20.n3.9712>. ISSN: 1519-9029.

Submetido em: agosto/2016

Aprovado em: outubro/2016 